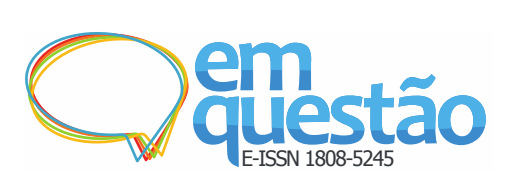

\title{
Interfaces disciplinares selecionadas da gestão do conhecimento: características, contribuições e reflexões
}

\author{
Lillian Maria Araujo de Rezende Alvares \\ Doutora; Universidade de Brasília, Brasília, DF, Brasil \\ lillianalvares@unb.br \\ Jainne Aragão Carvalho Fernandes \\ Mestre; Agência Nacional de Vigilância Sanitária, Brasília, DF, Brasil \\ jainne.ac@gmail.com \\ Ângelo José Penna Machado \\ Mestre, Centro Universitário ICESP de Brasília, Brasília, DF, Brasil \\ machado.angelo@gmail.com> \\ Cleids Maria Lisbôa Cardoso Soares \\ Mestre; Instituto CEUB de Pesquisa e Desenvolvimento, Brasília, DF, Brasil \\ cleidslisboa@gmail.com \\ Tácito Furtado Silva \\ Graduado, Intelit Processos Inteligentes, Brasília, DF, Brasil \\ tacitofs@gmail.com \\ Mariana Giubertti Guedes Greenhalgh \\ Doutoranda, Biblioteca Nacional de Brasília, Brasília, DF, Brasil \\ mari_biblio@hotmail.com \\ Eduardo Wallier Vianna \\ Doutor, Ministério Público do Distrito Federal e Territórios, Brasília, DF, Brasil \\ eduardowallier@hotmail.com
}

\begin{abstract}
Resumo: Analisa a contribuição de disciplinas estruturantes da gestão do conhecimento a partir da abordagem dos quatro paradigmas de Sagsan. Nesta perspectiva, a amplitude interdisciplinar da gestão do conhecimento é revelada, dando a possibilidade de conhecer seus fundamentos teóricos. Optou-se por analisar as ciências cognitivas, representando o paradigma humanista; a estatística, representando o paradigma sociotécnico; a administração e economia, representando o paradigma organizacional e a segurança da informação digital, representando o paradigma tecnológico. A metodologia utilizada foi revisão de literatura no período de 2008 a 2018 sobre as interfaces disciplinares da gestão do conhecimento em documentos recuperados na base de dados Bielefeld Academic Search Engine (BASE), um dos maiores mecanismos de busca de informação científica do mundo, com mais de 140 milhões de documentos indexados de mais de 6.000 fontes, sendo cerca de $60 \%$ em acesso aberto. Os resultados apontam que o futuro da gestão do conhecimento dependerá ainda mais dos avanços obtidos nas disciplinas em estudo.
\end{abstract}

Palavras-chave: Gestão do conhecimento. Interdisciplinaridade. Paradigmas da gestão do conhecimento. 


\section{Introdução: a fundação interdisciplinar da gestão do conhecimento}

A abrangência da Gestão do Conhecimento (GC) revela um conjunto heterogêneo de interesses, perspectivas e questões de pesquisa. Muito do conhecimento necessário ao pleno entendimento e aproveitamento da área tem várias origens conceituais. Desde as primeiras definições nos anos 1970, a área esteve associada aos fundamentos de outras disciplinas, como se pode atestar no entendimento dos pioneiros, que afirmam que a GC recebeu no seu berço intelectual influência da biblioteconomia, ciência da informação, comunicação, economia, educação, filosofia e psicologia, entre outras disciplinas (WALLACE, 2007).

A gestão do conhecimento, de acordo com a Enciclopédia de Gestão do Conhecimento de Schwartz (2006b) é multidisciplinar ${ }^{1}$, recebendo contribuições das ciências cognitivas, educação, inteligência artificial, psicologia, tecnologia e sistemas de informação e teoria organizacional. Prusak (2001) encontrou antecedentes da GC em economia, sociologia, filosofia e psicologia, segundo o autor, nessa ordem de importância.

A análise bibliométrica de Ponzi (2002) sobre as obras publicadas em gestão do conhecimento entre 1994 e 1998, depois ampliada por Gu (2004) para o período de 1975 até 2002, identificou as dez principais influências interdisciplinares relacionadas a seguir em ordem de ocorrência: gestão, negócios, sistemas de informação, biblioteconomia e ciência da informação, planejamento, teoria e métodos da ciência da computação, engenharia industrial, pesquisa operacional, administração, psicologia aplicada e administração pública.

Quintas, Lefrere e Jones (1997) consideram relevante apontar aspectos da aprendizagem, ciência da informação, computação, comunicação, economia, epistemologia, estudos organizacionais (incluindo a antropologia, biologia e sociologia), filosofia, inteligência artificial, linguística e psicologia cognitiva, entre tantos outros para compreender a agenda e os desafios estratégicos da gestão do conhecimento. 
De fato, muitos pesquisadores apontam a GC como interdisciplinar por condição, como Baskerville e Dulipovici (2006), que reconhecem que o campo está baseado em fundamentos teóricos do comportamento, cultura, desempenho e estrutura organizacional, da economia da informação e da gestão estratégica e da qualidade.

Essa natureza interdisciplinar da GC reflete seus dois principais paradigmas, o sócio-organizacional e o tecnológico, ao que Hazlett, McAdam e Gallagher (2005) chamam de paradigma orgânico e paradigma computacional ${ }^{2}$. O primeiro destaca a importância das pessoas e questões organizacionais dentro da gestão do conhecimento: interações, estruturas, processos de trabalho e cultura organizacional. O paradigma computacional, por sua vez, salienta o uso das tecnologias de informação e comunicação, sobretudo para o compartilhamento e disseminação do conhecimento.

Figura 1- Paradigmas da gestão do conhecimento de Hazlett, McAdam e Gallagher (2005)

\begin{tabular}{|c|c|}
\hline \multicolumn{2}{|c|}{ Características } \\
\hline Paradigma computacional & Paradigma orgânico \\
\hline Centrado em tecnologia & Centrado em pessoas \\
Linear (mecanicista) & Não linear (descontínuo) \\
Conhecimento explícito & Conhecimento tácito e explícito \\
Não contextual & Altamente contextual \\
Ambiente estático & Ambiente dinâmico \\
Otimização & Adaptação \\
\hline
\end{tabular}

Fonte: Traduzido de Hazlett, McAdam e Gallagher (2005, p. 37).

\subsection{As quatro camadas da gestão do conhecimento}

A pesquisa de Sagsan (2009) organiza a interdisciplinaridade da gestão do conhecimento em paradigmas predefinidos com base em quatro camadas subsequentes que ajudam a estabelecer e avançar no entendimento da área, proposta por Schwartz em 2006. Na visão de Schwartz (2006a), na primeira camada estão os filósofos, a filosofia e os pressupostos fundamentais que contribuem para a escolha de processos práticos de gerenciamento de conhecimento (Figura 2). De fato, o essencial na implementação das ações de GC é ter a consciência do caráter perpetuamente inacabado dos saberes, pois muito do aprendizado organizacional está relacionado à busca permanente do conhecimento individual e organizacional. 
Figura 2 - Camada 1 da gestão do conhecimento

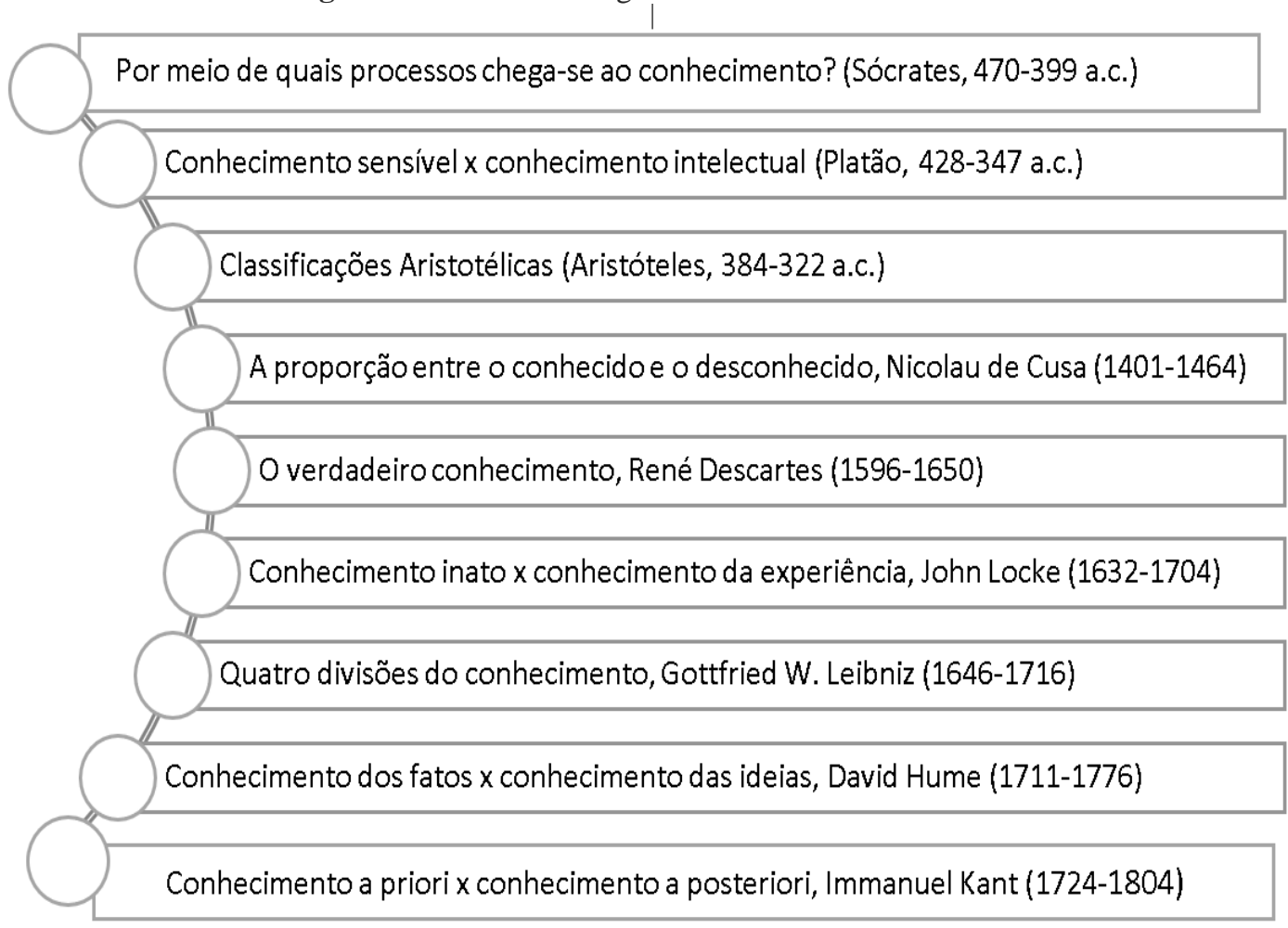

Fonte: Elaborado pelos autores.

$\mathrm{Na}$ segunda camada estão os processos de aquisição, organização e distribuição da informação (Figura 3), que devem ser implementados e adaptados para atender à terceira camada subsequente (Figura 4), de necessidades gerenciais, sociais e organizacionais, atendidas pela GC, destacando-se algumas das seguintes interfaces com a gestão do conhecimento: aprendizagem organizacional, capital intelectual, comunidades de prática, cultura organizacional, estratégia, motivação e vantagem competitiva, entre outros pontos de contato. 


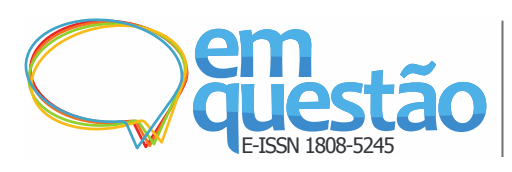

Interfaces disciplinares selecionadas da gestão do conhecimento: características, contribuições e reflexões

Lillian Maria Araujo de Rezende Alvares, Jainne Aragão Carvalho

Fernandes, Ângelo José Penna Machado, Cleids Maria Lisbôa

Cardoso Soares, Tácito Furtado Silva, Mariana Giubertti Guedes Greenhalgh, Eduardo Wallier Vianna

Figura 3 - Camada 2 da gestão do conhecimento
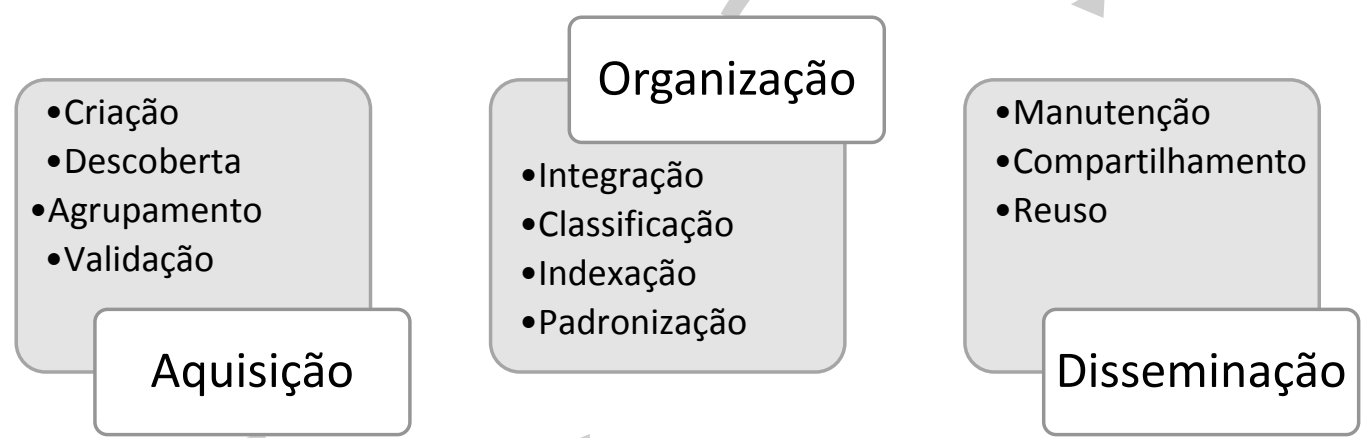

Fonte: Elaborado pelos autores com base em Schwartz (2006a)

Figura 4 - Camada 3 da gestão do conhecimento

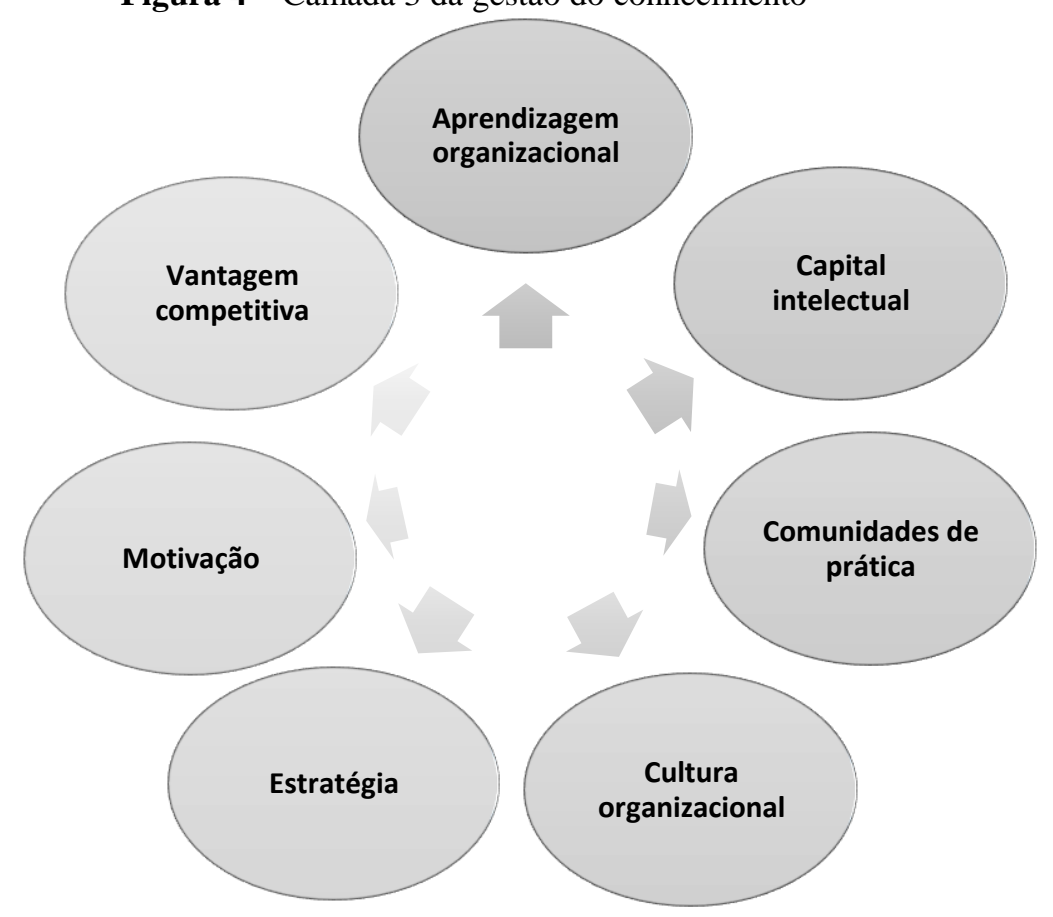

Fonte: Elaborado pelos autores.

Na camada 4 estão as tecnologias de informação e comunicação necessárias à GC (Figura 5), que tratam da representação da informação, recuperação da informação, disseminação da informação e segurança, entre outros aspectos. 
Lillian Maria Araujo de Rezende Alvares, Jainne Aragão Carvalho

Fernandes, Ângelo José Penna Machado, Cleids Maria Lisbôa

Cardoso Soares, Tácito Furtado Silva, Mariana Giubertti Guedes Greenhalgh, Eduardo Wallier Vianna

Figura 5 - Camada 4 da gestão do conhecimento

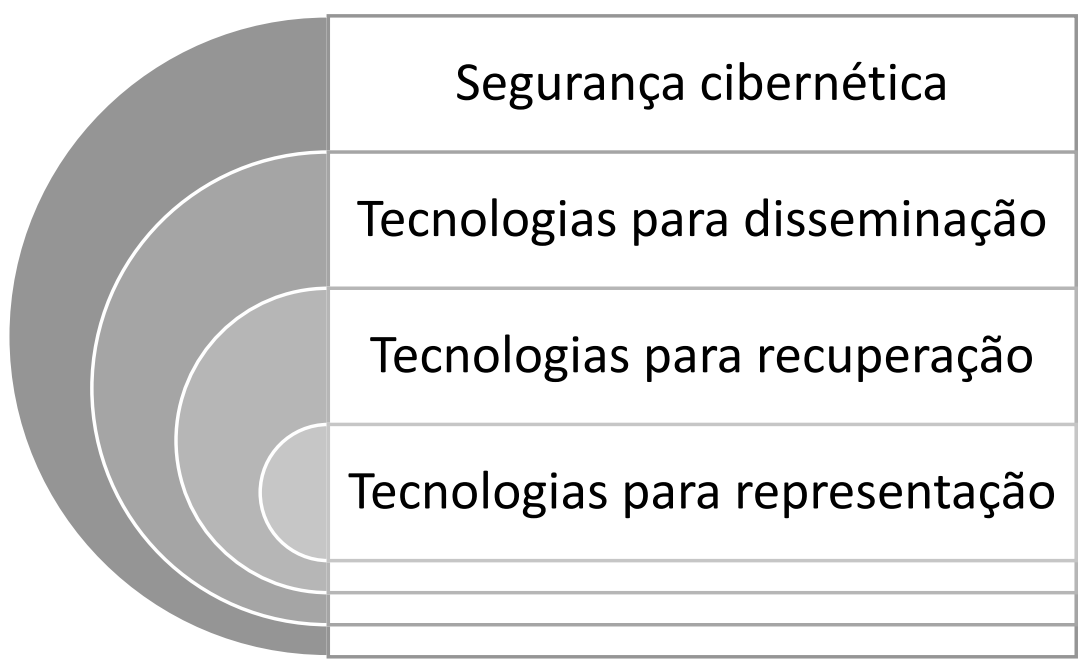

Fonte: Elaborado pelos autores.

As camadas de Schwartz (2006a), em suma, mostram que existe um núcleo filosófico (camada 1) que ampara a camada técnica seguinte (camada 2), que por sua vez interage dinamicamente com o estrato organizacional subsequente (camada 3), sendo todas envolvidas estruturalmente pela tecnologia (camada 4), fornecendo assim os fundamentos da disciplina da gestão do conhecimento (Figura 6).

Figura 6 - Camadas da gestão do conhecimento de Schwartz (2006)

Camada 1 - Os filósofos, a filosofia e os pressupostos

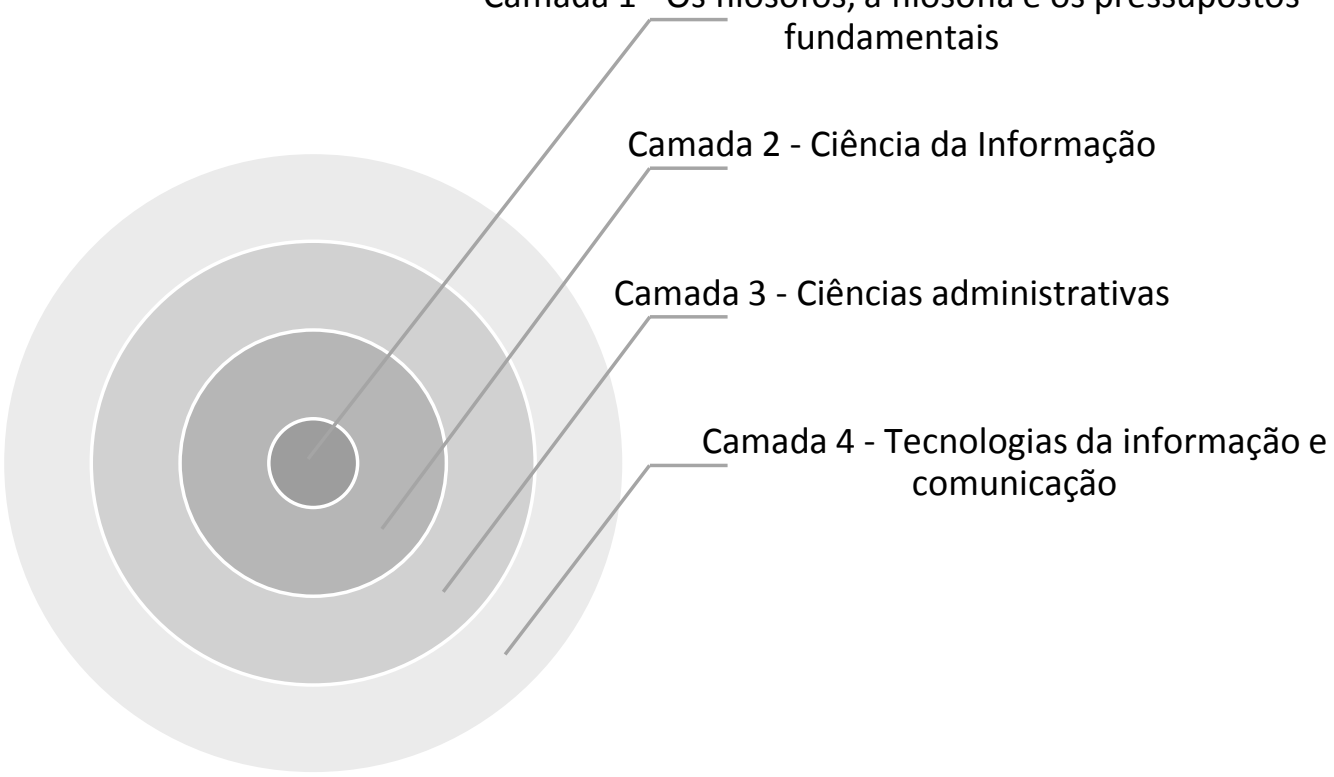

Fonte: Elaborado pelos autores com base em Schwartz (2006a) 


\subsection{Os quatro paradigmas da gestão do conhecimento}

Antes de avançar, cabe compreender o conceito de paradigma, amplamente tratado por Thomas Kuhn (1970) no seu livro A estrutura das revoluções científicas $^{3}$. Lá, segundo Masterman (1979), há vinte e uma (21) definições diferentes do termo. Esta pesquisa trouxe a concepção de paradigma como uma referência aos membros de uma comunidade científica de maneira que eles possam se organizar e compartilhar seu conhecimento. Nesse sentido, paradigma é uma estrutura para orientar um modo de pensar, uma visão de mundo que assegure a uma comunidade científica seu avanço.

Os quatro paradigmas de Sagsan (2009), baseados nas camadas da gestão do conhecimento de Schwartz (2006a), são o paradigma humanista, o paradigma sociotécnico, o paradigma organizacional e o paradigma tecnológico. Isto é, a gestão do conhecimento tem que ser compreendida não a partir de um único alicerce, o que seria impossível dada sua natureza interdisciplinar, mas de quatro pilares, entre os quais se distribuem as diversas disciplinas que lhe dão sustentação. A Figura 7 apresenta a equivalência entre as propostas de Sagsan (2009) e Schwartz (2006a).

Figura 7 - Equivalência entre as propostas de Sagsan (2009) e Schwartz (2006a)

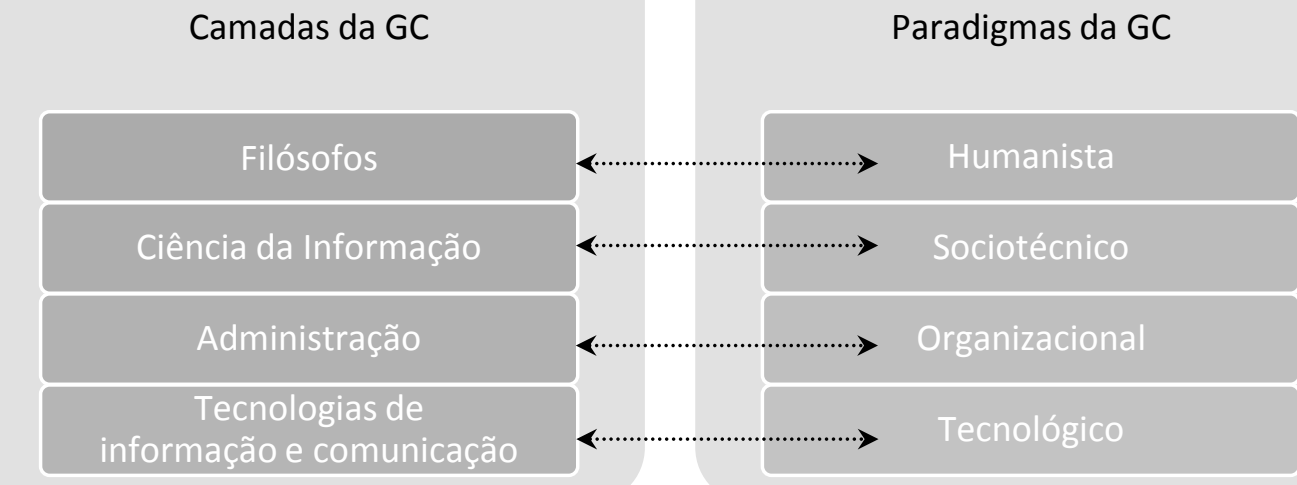

Fonte: Elaborado pelos autores.

O paradigma humanista é baseado em uma visão subjetiva que se interessa pela forma tácita do conhecimento. Encontra-se disperso nas atividades de aprendizagem individual, na personalidade, na capacidade, nas estruturas cognitivas individuais, entre outros. As disciplinas que estão aqui 
compreendidas são as ciências cognitivas, filosofia, pedagogia e psicologia, entre outras.

O paradigma sociotécnico é baseado no conhecimento necessário à realização dos processos produtivos e seus elementos constitutivos. É composto pelos dois subsistemas que o nomeiam, o social e o técnico, sendo o subsistema social constituído pelas relações entre pessoas que desempenham as tarefas e o técnico, por materiais, ferramentas, energia, equipamentos, instalações e tecnologia. $\mathrm{Na}$ gestão do conhecimento, o subsistema social e o subsistema técnico referem-se ao trato das informações estruturadas, não estruturadas ou semiestruturadas e incluem a compreensão das disciplinas de arquivologia, biblioteconomia, ciência da informação, comunicação, estatística, linguística e sociologia, entre outras.

O paradigma organizacional enfatiza como o conhecimento explícito, socialmente criado pelos trabalhadores e difundido de forma colaborativa nas organizações, deve ser processado por meio de atividades de criação, estruturação, compartilhamento, uso e auditoria do conhecimento. Essas ações por sua vez estão contidas nas disciplinas de administração, contabilidade e economia, entre outras.

O paradigma tecnológico é baseado nos avanços tecnológicos e exerce papel determinante na recuperação, compartilhamento e disseminação de informações estruturadas. Como exemplo, podem-se citar as disciplinas de ciência da computação, engenharia de redes, sistemas de informações, sistemas de suporte à decisão, tecnologias web, sistemas de gerenciamento de banco de dados e segurança de informação digital, entre outras.

Cabe destacar que a concepção de paradigmas da gestão do conhecimento tem acompanhado os cientistas sociais há muito, já que estes se preocupam com as diferenças nas suposições ontológicas e epistemológicas que explicam diferentes perspectivas e teorias na pesquisa social e organizacional.

Sagsan (2009) lembra que apenas poucos estudos se concentraram no entendimento da gestão do conhecimento em termos de paradigma, entre eles: Ives e Torrey (1998), Koenig (1999), Sattar e Higgins (2001), Dalkir (2005), 
Stankosky (2005), Hazlett, McAdam e Gallagher (2005) e Gloet e Berrell (2003).

Após examinar a interdisciplinaridade da gestão do conhecimento, por meio dos paradigmas propostos por Sagsan, o objetivo desta pesquisa foi analisar as interfaces de algumas das disciplinas que constituem a área, sem a pretensão de esgotar o assunto, a fim de compreender a amplitude interdisciplinar da gestão do conhecimento e, por conseguinte, os fundamentos teóricos que a sustentam. Optou-se pelas ciências cognitivas (representando o paradigma humanista), pela estatística (representando o paradigma sociotécnico), pela administração e economia (representando o paradigma organizacional), e pela segurança da informação digital (representando o paradigma tecnológico).

A metodologia adotada foi revisão da literatura disponível em acesso aberto no período de 2008 a 2018 sobre as interfaces disciplinares da gestão do conhecimento em documentos recuperados na base de dados Bielefeld Academic Search Engine (BASE), um dos maiores mecanismos de busca de informação científica do mundo, com mais de 150 milhões de documentos indexados de mais de 6.000 fontes, sendo cerca de $60 \%$ em acesso aberto. Na primeira etapa da pesquisa, os termos utilizados para busca em fontes de acesso aberto foram knowledge management and epistemology (95 resultados) e knowledge management and interdisciplinarity (14 resultados) e knowledge management and paradigms (183 resultados). Da análise dos 292 documentos recuperados, seis eram do mesmo autor, Mustafa Sagsan, cujo trabalho foi a base do desenvolvimento desta pesquisa. Na segunda etapa da pesquisa, o estudo das disciplinas fundamentais à gestão do conhecimento identificadas na etapa 1, a metodologia previu aprofundamento nos estudos clássicos da administração, ciências cognitivas, economia, estatística e segurança cibernética, com vistas a identificar as interfaces com a gestão do conhecimento. Dentre estas, distinguiuse a contribuição da ciência da informação, mas esta não foi objeto de estudo nesta investigação, dada sua magnitude para os estudos de gestão do conhecimento. 

conhecimento: características, contribuições e reflexões Lillian Maria Araujo de Rezende Alvares, Jainne Aragão Carvalho Fernandes, Ângelo José Penna Machado, Cleids Maria Lisbôa Cardoso Soares, Tácito Furtado Silva, Mariana Giubertti Guedes Greenhalgh, Eduardo Wallier Vianna

\section{Resultados alcançados: interfaces disciplinares}

São muitas as disciplinas que conformam os paradigmas da gestão do conhecimento em uma perspectiva interdisciplinar. O paradigma organizacional, por exemplo, traz as ciências empresariais e os estudos organizacionais, das quais se destacam as disciplinas de administração, comunicação, contabilidade, economia e marketing. O paradigma humanista traz, entre outros, os estudos em artes, antropologia, filosofia, geografia, história, pedagogia e psicologia. Já no paradigma sociotécnico estão as disciplinas das ciências da informação, estatística, linguística e sociologia, entre tantas, e no paradigma tecnológico estão, por exemplo, as ciências da computação, engenharia de redes, sistemas de informação, segurança de informação (que inclui a segurança da informação digital).

Esse estudo optou pelas disciplinas (1) cuja influência na gestão do conhecimento é célebre, (2) que estão registradas em conceitos e definições consolidadas, e que (3) são representativas dos conceitos de conhecimento tácito e explícito, de informação estruturada e não estruturada e de características de objetividade e subjetividade (Figura 8).

Figura 8 - Disciplinas selecionadas

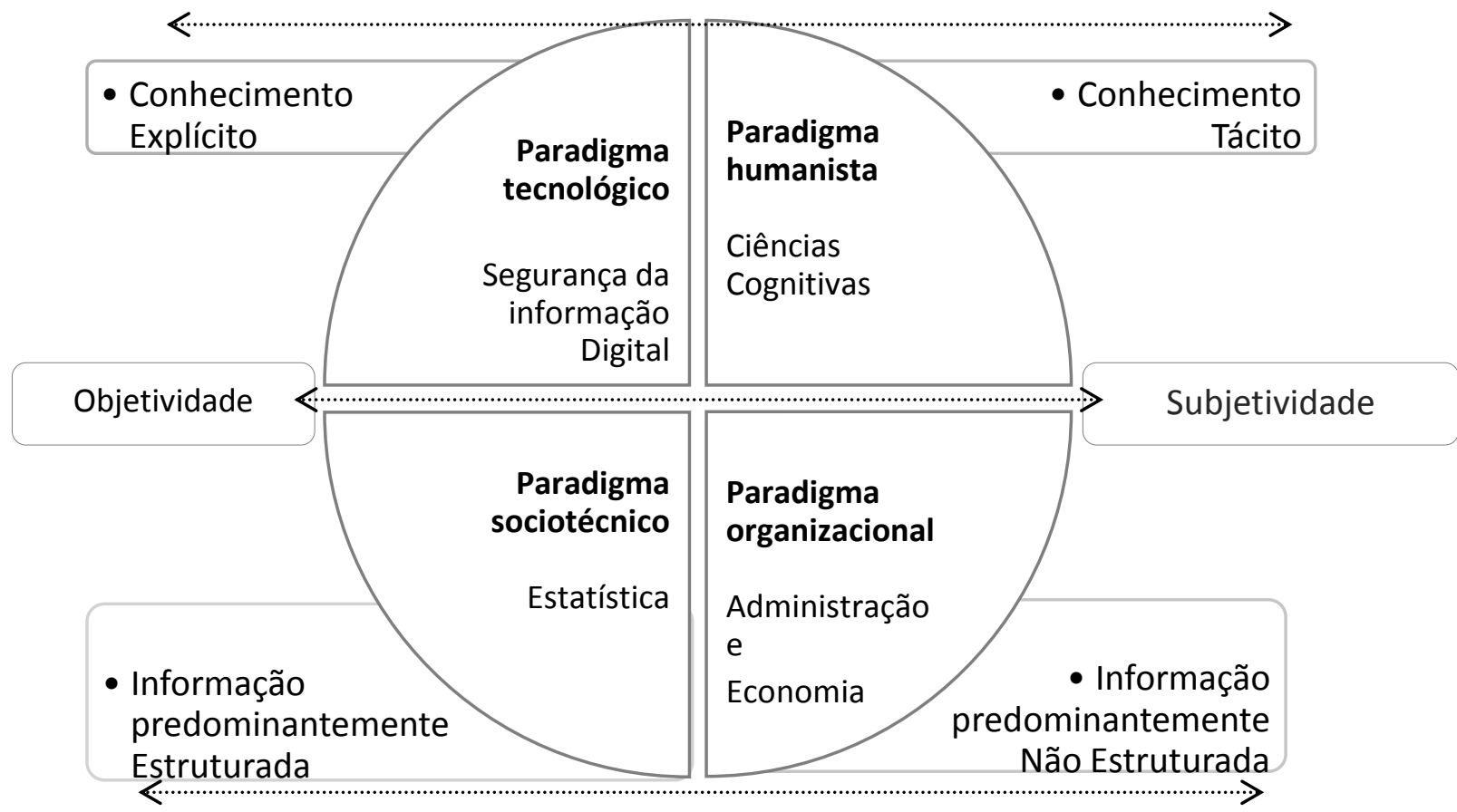

Fonte: Elaborado pelos autores, com base em Sagsan (2009). 


\subsection{Paradigma humanista: ciências cognitivas}

As ciências cognitivas compartilham uma preocupação básica sobre a compreensão dos processos cognitivos, sua realização no cérebro, a estrutura da mente e suas várias manifestações, como a inteligência. A psicologia comportamentalista e cognitivista em particular busca respostas para as questões voltadas ao entendimento de como funcionam os processos de aprendizagem nos seres humanos.

A pedagogia, por sua vez, principalmente a partir da incorporação da psicologia como base epistemológica, revelou alguns pesquisadores, oriundos de diversas áreas do conhecimento, que influenciaram e ainda continuam a influenciar os pressupostos teóricos sobre aprendizagem. Nas primeiras décadas do século XX, dois grandes nomes se destacaram: o biólogo suíço Jean Piaget e o advogado e psicólogo bielorrusso Lev Semenovich Vigotski, respectivamente associados ao construtivismo e ao socioconstrutivismo da educação.

Vigotski (2010) elencou três tipos básicos de educação pelo trabalho. O primeiro deles é a escola profissionalizante ou escola de ofício, onde o trabalho é o objeto da aprendizagem e o principal objetivo pedagógico é preparar o educando para uma determinada tarefa laboral. Na concepção do autor,

[...] a educação pelo trabalho não difere nada de qualquer outra, porque toda pedagogia sempre procura estabelecer um novo sistema de comportamento, independentemente da expressão que esse sistema possa ter [...] (VIGOTSKI, 2010, p. 247).

ou seja, o objeto de ensino está diretamente vinculado às futuras atividades do aprendiz, no que tange ao conhecimento como mudança de comportamento.

No outro tipo, trata-se da situação ocupada pelo trabalho como método de ensino e não como objeto, ou seja, as habilidades laborais servem como meio para melhor assimilar alguns conteúdos. O autor cita o exemplo de um professor de história que deseja aprofundar o conhecimento sobre uma determinada época. Para se adquirir o conhecimento abstrato, este professor leva os alunos a desenharem mapas, esculpirem maquetes de edificações antigas, reproduzirem armamentos e vestuários da época estudada, entre outros. Desta forma, Vigotski (2010) acreditava que o trabalho manual aumentava a percepção do aluno, 


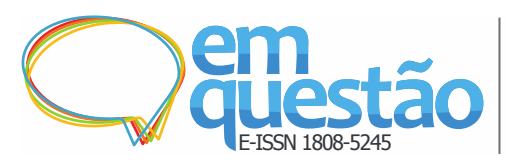

Interfaces disciplinares selecionadas da gestão do conhecimento: características, contribuições e reflexões Lillian Maria Araujo de Rezende Alvares, Jainne Aragão Carvalho Fernandes, Ângelo José Penna Machado, Cleids Maria Lisbôa Cardoso Soares, Tácito Furtado Silva, Mariana Giubertti Guedes Greenhalgh, Eduardo Wallier Vianna

levando-o além do sentido visual e incluindo o tato e o movimento como fatores que contribuem para o aprendizado, apesar de a orientação educacional permanecer fora do âmbito do trabalho e focado no ensino da história.

O terceiro e último tipo de educação para o trabalho consiste em uma visão do trabalho como fundamento do processo educativo, ou seja, o trabalho não é introduzido como objeto de ensino e nem como método ou meio de aprendizagem, mas como matéria de educação. Neste sentido, segundo o autor, "[...] não só o trabalho se introduz na escola, mas também a escola no trabalho." (VIGOTSKI, 2010, p. 249).

A partir de um simpósio sobre Ciência da Informação, realizado em 1956 no Massachusetts Institute of Tecnology (MIT), ocorreu uma revolução nas ciências cognitivas. Este simpósio, que teve a participação de psicólogos, linguistas e especialistas em inteligência artificial, forneceu a ligação teórica entre a psicologia e a informática, o que impulsionou, sobremaneira, a evolução de uma nova disciplina científica, batizada como ciências cognitivas. A ideia principal era tentar entender melhor os mecanismos do cérebro e de que modo o ser humano aprende e memoriza.

No começo dos anos de 1980, a revolução cognitiva iniciada em 1956 e aperfeiçoada ao longo das décadas de 1960 e 1970 possibilitou o surgimento de uma nova teoria da aprendizagem. O principal postulado desta teoria é a consideração do homem e do computador como sistemas abertos, que podem se comunicar com o ambiente, ou seja, ambos tratam a informação vinda do exterior e se regulam em função desses dados. Para a teoria cognitiva da aprendizagem, todo sistema inteligente (humano ou artificial) possui representações simbólicas do estado do mundo sobre as quais se opera o pensamento. Desta forma, as pesquisas em psicologia cognitiva, segundo Gauthier, Bissonnette e Richard (2018, s/p.), baseando-se no funcionamento do computador,

[...] estudam como o ser humano recolhe, codifica, interpreta, modifica e armazena a informação proveniente do ambiente e de que formele as leva em conta para tomar decisões. 
Uma das figuras de proa da aplicação das ciências cognitivas no campo da educação, mais especificamente na área de aprendizagem, foi o psicólogo estadunidense Robert M. Gagné. Por meio de seus estudos na área de tratamento da informação, ele contribuiu de forma efetiva para uma melhor compreensão dos processos de aprendizagem, muito úteis para aprimorar os processos educacionais. Ele afirma que a aprendizagem é um processo que

[...] torna estes organismos capazes de modificar seu comportamento de modo relativamente rápido, de uma forma mais ou menos permanente, de tal modo que não tenha que ocorrer frequentemente em cada nova situação. (GAGNÉ, 1980, p. 5)

A prova de que a aprendizagem ocorreu consiste na verificação de uma mudança comportamental relativamente persistente. Infere-se, dessa observação, que o indivíduo procedeu a uma mudança interna e, portanto, que aprendeu. Em suma, a aprendizagem bem-sucedida modifica o comportamento e pressupõe-se que tenha sido efetiva e perene.

As ciências cognitivas em geral e a psicologia em particular estão preocupadas com os diferentes tipos de conhecimento, bem como interessadas em como e por que as pessoas aprendem, esquecem, ignoram, agem ou deixam de agir. Colaboram efetivamente para a implantação e melhoria da GC no âmbito organizacional. Considerando-se que as organizações são espaços de aprendizagem e partindo-se do pressuposto de que o mundo contemporâneo exige aprendizado constante e contínuo em diversas áreas do conhecimento, torna-se fundamental que esse processo de aprendizagem esteja baseado em métodos científicos, elaborados de acordo com as particularidades e necessidades da organização, utilizando técnicas pedagógicas e andragógicas ${ }^{4}$ que facilitem o processo ensino/aprendizagem no âmbito organizacional.

\subsection{Paradigma sociotécnico: estatística}

Para representar o paradigma sociotécnico, esta pesquisa optou pela disciplina estatística, cuja etimologia, de origem latina, representa a coleta e a apresentação de dados quantitativos, principalmente relacionados a interesses do Estado. Por isso, seu conceito popular sempre traz à lembrança quadros ou 
gráficos com representações numéricas relativas à demografia e à economia, publicados por órgãos oficiais (MEMÓRIA, 2004).

Em seu desenvolvimento, a história da estatística é vista em cinco etapas. A primeira é a dos primórdios, com diversas contribuições, desde a astronomia (no século XVIII), passando pela noção de probabilidade (com a influência das ciências sociais e com a preocupação com o social da Escola de Aritmética Política) até o uso preferencial da distribuição cumulativa de frequência, a enumeração explícita e parcialmente quantitativa dos conceitos de regressão e de correlação.

A segunda etapa é a Escola Biométrica, com predomínio das técnicas de correlação e de ajustamento de curvas e dos resultados de descrição de amostras grandes, principalmente representada pelos estudos do matemático Karl Pearson, considerado desde então o pai da estatística (ocorre no final do século XIX e início do XX).

A experimentação vem a ser a terceira etapa, com os fundamentos teóricos de Ronald Aylmer Fisher, o mais importante estatístico do século XX, e o método da máxima verossimilhança no ajustamento das frequências. Nas décadas de 1920 e 1930, ressaltam-se a distribuição do coeficiente de correlação, a análise de variância e delineamentos experimentais, o teste de hipóteses estatísticas, o problema de que um teste deve envolver duas hipóteses (a hipótese nula que está sendo testada e a complementar ou alternativa, com probabilidade de rejeição da hipótese nula) (MEMÓRIA, 2004) e a utilização sistemática da probabilidade nos papéis de coleta, no resumo e na análise de dados empíricos (LOPES; MEIRELLES, 2005).

A quarta etapa foi o desenvolvimento de levantamentos por amostragem nos anos de 1940 e 1950 o desenvolvimento das experimentações e a teoria da estatística, segundo a qual, em experimentos, lida-se com populações imaginárias e infinitas, quando na realidade as populações são reais e finitas. A última etapa, da era atual, é marcada pela gradativa influência da utilização de computadores, facilitando a aplicação de métodos e a obtenção de resultados (MEMÓRIA, 2004). 
Assim, a estatística, antes meramente descritiva e, em sua origem remota, registro de ocorrências, passou a utilizar-se de métodos científicos para a coleta de dados e chegou à atualidade com o seguinte objetivo: “[...] fornecer métodos e técnicas para se lidar, racionalmente, com situações sujeitas a incertezas." (MORAIS, 2010, p. 4).

Desse contexto de definições e de aplicações específicas, podem-se inferir as seguintes características principais da estatística: é descritiva, realiza registros e testes, é interpretativa, trabalha com métodos e com amostras, utilizase de hipóteses e de variáveis, pondera resultados por meio de médias e fundamenta-se na teoria da probabilidade.

A compreensão da contribuição da estatística às etapas do processo de gestão do conhecimento requer explicar que os processos da GC se desenvolvem em etapas, de três a oito, a depender do autor, conforme Fukunaga (2017), mas criação, retenção e disseminação (com denominações variadas) são comuns a todos os modelos analisados.

Quadro 1- Etapas do processo de Gestão do Conhecimento

\begin{tabular}{|c|c|c|}
\hline Ano & Autor & Processos da Gestão do Conhecimento \\
\hline 1993 & Wiig & $\begin{array}{c}\text { criação e abastecimento|compilação e transformação|divulgação } \\
\text { |aplicação }\end{array}$ \\
\hline 2000 & Terra & captura|organização|compartilhamento|disseminação|proteção|inovação \\
\hline 2001 & Parikh & aquisição|organização|divulgação|aplicação \\
\hline 2002 & Probst et al. & $\begin{array}{c}\text { identificação|aquisição|desenvolvimento|compartilhamento e } \\
\text { distribuição|utilização|retenção|objetivos|avaliação }\end{array}$ \\
\hline 2003 & Argote $e t$ al. & criação|retenção|transferência \\
\hline 2003 & Watson & aquisição|armazenagem|recuperação|aplicação|geração|revisão \\
\hline 2012 & $\begin{array}{l}\text { Davenport e } \\
\text { Prusak }\end{array}$ & geração|codificação e coordenação|transferência \\
\hline
\end{tabular}

Fonte: Elaborado pelos autores, com base em Fukunaga (2017)

A estatística contribui para a criação do conhecimento por meio da cessão de dados e informações obtidos da realidade empírica, com a utilização de métodos científicos e de testes, com aplicação de hipóteses e de variáveis, com interpretação desses dados e sua ponderação, tendo por base a probabilidade. "Dados são sinais que não foram processados, correlacionados, integrados, avaliados ou interpretados de qualquer forma. [...] representam a matéria-prima a ser utilizada na produção de informações [...]" (TARAPANOFF, 2000, p. 117); informação é um conjunto de dados que, depois 


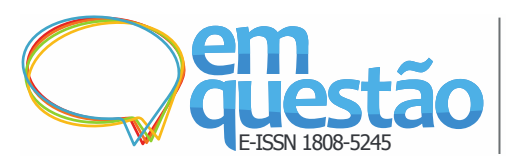

Interfaces disciplinares selecionadas da gestão do conhecimento: características, contribuições e reflexões Lillian Maria Araujo de Rezende Alvares, Jainne Aragão Carvalho Fernandes, Ângelo José Penna Machado, Cleids Maria Lisbôa Cardoso Soares, Tácito Furtado Silva, Mariana Giubertti Guedes Greenhalgh, Eduardo Wallier Vianna

de recebidos e processados, foram entendidos; o conhecimento é um conjunto de experiências, de valores e de informações contextualizadas, o qual proporciona uma base estrutural que serve para avaliar e incorporar outras experiências e informações (DAVENPORT; PRUSAK, 2003).

Os avanços da tecnologia da informação e o considerável aumento das capacidades de produção, de armazenamento e de transmissão de informações, associados à consequente ampliação de demandas, passaram a exigir da Estatística metodologias ainda mais precisas e profissionais mais capacitados para a obtenção de indicadores complexos.

Alonso (1999) afirma que a importância da criação do conhecimento para o processo produtivo vem crescendo acentuadamente, exigindo reestruturação das organizações. Segundo essa autora, a tendência desenvolvida em países de primeiro mundo é a de empresas se associarem a instituições de pesquisa, como forma de se manterem atualizadas em relação aos avanços científicos e tecnológicos e se anteciparem na introdução e na oferta de produtos e de serviços.

No Brasil, o Instituto Brasileiro de Geografia e Estatística (IBGE, 2019) realiza pesquisas periódicas nas mais distintas áreas e entre suas principais funções, encontram-se a produção e a análise de dados e de informação.

Já a retenção do conhecimento “[...] envolve a incorporação de conhecimento em um repositório para que ocorra alguma persistência ao longo do tempo." (FUKUNAGA, 2017, p. 14). Reter o conhecimento requer o uso eficiente de vários meios de armazenagem. O conhecimento já codificado e organizado deve ficar armazenado e disponível para acesso dos indivíduos.

Gonzalez (2016, p. 43) chama a atenção para alguns pontos que não só justificam a retenção do conhecimento como demonstram sua importância: “[...] a perda de conhecimento pode reduzir a vantagem competitiva e colocar uma organização em dificuldades econômicas [...]". Pesquisas demonstram que é consensual o entendimento de que a saída de funcionários pode causar perdas de conhecimento à organização; um alto grau de turnover pode ter como efeito "“uma amnésia operacional e institucional perigosa"” (GONZALES, 2016, p. 
43). Ainda nesse contexto, a aposentadoria de funcionários pode ocasionar perda de parte do conhecimento relativo a atividades específicas, por exemplo.

Em resumo, conforme Gonzalez e Martins (2015, p. 835), a etapa de retenção/armazenamento do conhecimento diz respeito “[...] ao processo de formação de memória organizacional [...]", sendo o conhecimento “[...] formalmente armazenado em sistemas físicos de memória relacionados a sistemas de informação [...]" e, ao mesmo tempo, "[...] informalmente retido na forma de valores, normas e crenças que se associam à cultura e estrutura organizacional [...]", retido ainda nos processos, nas ferramentas e nas rotinas da organização.

Afirmam Gonzalez e Martins (2015, p. 835) que

[...] a distribuição do conhecimento diz respeito ao processo pelo qual novas informações de diferentes origens são compartilhadas e, eventualmente, podem dirigir a criação de novo conhecimento, entendimento e informação.

Segundo esses autores, antigos trabalhos sobre o processo de transferência do conhecimento se centravam nos fatores cognitivos e nos sociais. Já atualmente, o foco são os fatores organizacionais que podem facilitar ou inibir o referido processo. Esse inclui vários aspectos: capacidade de absorção da organização, desenvolvimento de uma cultura organizacional de compartilhamento, expertise dos indivíduos e motivação. Nesse contexto, destaque-se a tecnologia, que facilita bastante o processo de transferência da informação.

Fukunaga $(2017$, p. 7), em uma breve revisão da literatura, refere-se à transferência de conhecimentos e ao sucesso dessa transferência como uma "qualidade do conjunto da relação." Tal qualidade enfatiza o padrão de conexões entre várias unidades. "O fluxo de conhecimento entre dois indivíduos é facilitado quando os indivíduos estão inseridos em uma densa rede de conexões de terceiros [...] ". Há argumentos no sentido de que a transferência do conhecimento é mais propícia entre entidades de uma mesma organização, entre associadas de uma mesma franquia ou entre uma cadeia de organizações independentes. As relações podem se desenvolver em forma de memória 


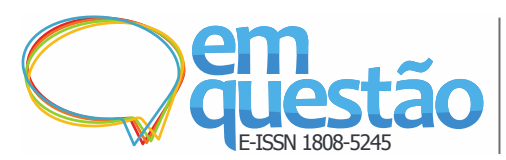

Interfaces disciplinares selecionadas da gestão do conhecimento: características, contribuições e reflexões Lillian Maria Araujo de Rezende Alvares, Jainne Aragão Carvalho Fernandes, Ângelo José Penna Machado, Cleids Maria Lisbôa Cardoso Soares, Tácito Furtado Silva, Mariana Giubertti Guedes Greenhalgh, Eduardo Wallier Vianna

transacional ou em consenso quanto a quem sabe o quê. A transferência de conhecimento, tanto quanto a retenção, é "mais eficiente quando os membros do grupo compartilham uma linguagem comum.” De acordo com Pina (2010), a falta de partilha e a inexistência de um mapeamento entre os distintos conhecimentos representam carências.

A estatística contribui para a transferência do conhecimento seja por meio de gráficos e tabelas, seja por dados numéricos utilizados no aprimoramento ou aumento da produção. Ignácio (2010, p. 1) afirma que, “[...] com a velocidade da informação, a estatística passou a ser uma ferramenta essencial na produção e disseminação do conhecimento."

\subsection{Paradigma organizacional: administração e economia}

As disciplinas relacionadas ao paradigma organizacional são estruturantes para o entendimento da gestão do conhecimento. Há uma forte associação entre o processo administrativo e suas funções (planejar, organizar, liderar, executar, controlar) e os processos da gestão do conhecimento (gerar, organizar, desenvolver e distribuir), pelo fato de que não há como direcionar uma organização para obtenção de resultados sem o domínio daquilo que é considerado o principal recurso e capital: o conhecimento do negócio e as suas variadas relações e implicações.

Sob esta ótica, há que se considerar este conhecimento a partir de três naturezas distintas, mas complementares: (1) o conhecimento intrínseco à prática administrativa, considerado técnico e que teoricamente tem um núcleo comum a todo tipo de organização, setor de economia, missão ou desafio a ser vencido (tratado pela Escola Clássica), complementado por especificidades do como fazer do setor; (2) o conhecimento das relações e reações humanas, internos ou externos às organizações (tratado pela Escola das Relações Humanas e no contexto do Pensamento Sistêmico); e (3) o conhecimento do ambiente socioeconômico (tratado pela Escola Contingencial e variações seguintes), pilares para constituição de organizações que possam contribuir significativamente em seu setor de atuação. 
De fato, a administração considera efetivamente o conhecimento interno e externo como fator crítico de sucesso, o que determina uma abordagem de organização de aprendizagem contínua com o objetivo de garantir a perenidade por intermédio do conhecimento do negócio diante das mudanças socioeconômicas e comportamentais do ser humano. O domínio do conhecimento pelos administradores, não somente na sua área de interesse e atuação, reduz o tempo de decisão, diminui o risco e, consequentemente, aumenta a competitividade, objetivo maior dos administradores.

Ainda no paradigma organizacional, cada vez mais os ativos de conhecimento são valorizados, ou seja, o foco da economia está nos ativos intangíveis, ao que Stewart (1998) denomina de era do conhecimento. Este autor ressalta, entretanto, que a revolução da informação não acabará com a revolução industrial, ela apenas contempla um novo enfoque econômico.

Drucker (1997, p. 141) afirma que

[...] precisamos de uma teoria econômica que coloque o conhecimento no centro do processo de produção de riqueza. Somente essa teoria poderá explicar a economia atual. Somente ela poderá explicar o crescimento econômico e a inovação.

Com essa passagem é possível perceber que Drucker (1997) já previa o surgimento de uma economia baseada em conhecimento e, mais do que isso, previa também a necessidade de que as organizações se voltassem para o conhecimento e não mais para ativos tangíveis como o capital financeiro.

O conhecimento, visto então como fonte de riqueza, traz consigo dois aspectos importantes para a economia:

1. O conhecimento e os ativos que o criam e distribuem podem ser administrados, da mesma forma que os ativos físicos e financeiros; e 2. Se o conhecimento é a maior fonte de riqueza, os indivíduos, as empresas e os países devem investir nos ativos que produzem e processam o conhecimento. Tais ativos não são necessariamente engenhocas de alta tecnologia, e esses investimentos não devem ser todos investimentos em alta tecnologia. (STEWART, 1998, p. 28). 
Existe um aspecto ainda mais importante do conhecimento que passou a ser tratado pelos economistas: estes passaram a tratar o conhecimento como um insumo estratégico, contemplando uma visão diferente da visão tradicional capitalista voltada para lucros tangíveis e quantificáveis como o dinheiro. De acordo com Nonaka e Takeuchi (1997, p. 37), grande parte das teorias econômicas tratou o conhecimento como um fator importante nos fenômenos econômicos, seja de maneira implícita, seja de maneira explícita.

Estudos da década de 1990 ressaltam a importância da gestão do conhecimento na aplicação da Teoria da Firma, que é um campo dos estudos das Teorias Econômicas que parte da noção de que,

Em uma economia de mercado, os consumidores, por um lado, e as firmas, por outro, se constituem respectivamente nas unidades do setor de consumo e do setor da produção. (EQUIPE, 1991, p. 103).

Assim, segundo os autores, a Teoria da Firma busca compreender o comportamento da firma quando esta desenvolve sua atividade produtiva, ou seja, busca estudar o comportamento da unidade do setor de produção.

Na visão de Marshall (1982), a Teoria da Firma teria uma atuação mais ativa, e não passiva, de modo que para ele, a firma interagiria e interferiria no ambiente, sofrendo suas consequências e influências. Nesse contexto, surge a importância do tratamento da informação e do conhecimento encontrados tanto na organização como no ambiente que circunda a firma, para que ela seja capaz de aumentar sua produtividade, reduzir seus custos e analisar os seus rendimentos. Todos esses aspectos podem ser levados em conta de forma mais eficiente com o auxílio dos processos de GC.

Na visão de Ruiz González, Font Graupera e Lazcano Herrera (2015), a economia baseada no conhecimento é, atualmente, considerada pedra fundamental no centro das organizações, permitindo que elas atinjam seus objetivos e levem a cabo suas estratégias. Afirmam também que no atual processo produtivo das organizações, 
Esse processo incorpora o conhecimento como um elemento de grande importância que ocupa um lugar essencial no crescimento econômico e na elevação progressiva do bem-estar social, uma vez que é central nos processos de inovação e geração de novos conhecimentos, que se materializam em novos produtos, procedimentos e organizações, para alimentar o desenvolvimento de uma nação. (RUIZ GONZÁLES; FONT GRAUPERA; LAZCANO HERRERA, 2015, p. 3 , tradução nossa ${ }^{5}$.)

Observa-se que na sociedade atual, o crescimento econômico tem incorporado os conceitos de GC e valorizado a obtenção dos ativos intangíveis. Assim, é possível dizer que aspectos da economia baseada em conhecimento podem alimentar o desenvolvimento de uma sociedade mais evoluída ${ }^{6}$.

\subsection{Paradigma tecnológico: segurança da informação digital}

A informação digital tornou-se ativo de inestimável valor para a sustentabilidade e desenvolvimento de nações e instituições. Incorpora tecnologias de informação e comunicação, caracterizando-se como um conjunto de recursos com elevada capacidade de transformação. Na esteira da informação digital, emerge o entendimento matricial de ciberespaço, no qual as informações são estruturadas em sistemas automatizados e conectados por redes de dados.

O ciberespaço, de fato, desenvolve-se e amplia-se baseado na acelerada e irreversível interconectividade mundial, denominada quarta revolução industrial, sendo o suporte para toda a gama de atividades públicas ou privadas, em praticamente todas as áreas da atividade humana. Possibilita a geração de variados produtos e serviços tecnológicos e em consequência, necessita de processos gerenciais singulares de controle, bem como de cuidados referentes à proteção dos dados e das informações digitais circulantes nesse ambiente artificial.

As análises sobre os riscos tecnológicos globais, sobretudo as realizadas nos encontros do Fórum Econômico Mundial ${ }^{7}$, vêm destacando ameaças à interconectividade mundial e preocupações crescentes com a privacidade dos dados individuais e corporativos.

De acordo com o padrão internacional ABNT NBR ISO 27.000 (2013), que trata da gestão da segurança da informação, a segurança da informação está 
fundada na tríade confiabilidade, integridade e disponibilidade ${ }^{8}$. Confidencialidade refere-se à propriedade de que a informação não esteja disponível ou revelada a indivíduos, entidades ou processos não autorizados. Integridade significa exatidão, significa que a informação se encontra completa e não sofreu nenhum tipo de corrupção ou alteração não autorizada. Por fim, disponibilidade é o requisito próprio da informação, que deve estar acessível, utilizável e em prontidão de atendimento, sob demanda de uma entidade autorizada.

Além desses, os especialistas acrescentam ainda os atributos de autenticidade, para garantir que a informação deve estar livre de adulteração; a irretratabilidade (ou não repúdio), atributo que estabelece evidências do tempo, do lugar e da entidade responsável pela produção, acesso, modificação ou uso da informação; a conformidade, o atributo de uma informação sustentar o fato ao qual se refere, a partir da completeza, da forma e do grau de controle exercido no seu processo de criação e a responsabilidade, propriedade pela qual o responsável pela informação deve prestar contas dessa informação (accontability).

Do paradigma tecnológico, devido ao seu potencial de trato das informações em meio digital, os sistemas de gerenciamento do conhecimento devem, de forma a mitigar ameaças e reduzir vulnerabilidades, ser protegidos de atividades maliciosas. Dentre as atividades maliciosas que podem comprometer a gestão do conhecimento apoiada em sistemas digitais, especialmente naqueles geograficamente distribuídos e conectados em rede, Vianna e Sousa (2017) destacam:

a) Interrupção indesejada dos serviços prestados: ação deliberada que causa indisponibilidade no acesso às informações, incluindo também a inserção prévia de códigos maliciosos na solução adquirida, pelos próprios fabricantes de hardware e software;

b) Furto de informação sigilosa ou ostensiva: ação criminosa que torna a informação indisponível, mesmo que temporariamente, aos usuários;

c) Extorsão (sequestro da informação): ação em expansão, conhecida como ransomware, que consiste em que artefatos maliciosos sequestrem o 


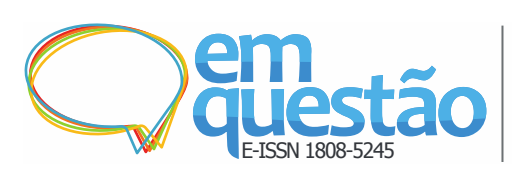

Interfaces disciplinares selecionadas da gestão do conhecimento: características, contribuições e reflexões Lillian Maria Araujo de Rezende Alvares, Jainne Aragão Carvalho Fernandes, Ângelo José Penna Machado, Cleids Maria Lisbôa Cardoso Soares, Tácito Furtado Silva, Mariana Giubertti Guedes Greenhalgh, Eduardo Wallier Vianna

ingresso a computadores e arquivos, cobrando pagamento para a liberação do acesso à informação sequestrada;

d) Modificações nas propriedades e atributos da informação: ação, intencional ou não, que altera os metadados de identificação como: autoria, data de criação, formato, classificação etc.;

Corroborando os aspectos de controle e os requisitos da segurança da informação digital supracitados, a ISO 30.401 (2018), que trata dos requisitos para sistemas de gestão do conhecimento, estabelece que a organização deve abordar quatro grupos de atividades: (1) distribuição, acesso, recuperação e uso; (2) armazenamento e preservação; (3) controle de alterações e de versões e (4) retenção e estruturação. Todos esses grupos de atividades são dependentes de políticas de segurança de informação; de abordagem e estrutura para implementação, manutenção e melhoria da segurança da informação (consistente com a cultura organizacional); de comprometimento e apoio visível de todos os níveis gerenciais; de bom entendimento dos requisitos de segurança, de análise e avaliação de riscos e de divulgação eficiente em todos os níveis para alcançar a conscientização (ASSOCIAÇÃO BRASILEIRA DE NORMAS TÉCNICAS, 2005).

Finalmente, vale destacar que no ambiente tecnológico hodierno, aos aspectos da segurança da informação relativos à gestão do conhecimento devem somar-se o compartilhamento seguro do conhecimento em tempo real; a confidencialidade dos registros sensíveis institucionais, particularmente aqueles suportados por sistemas online; a integridade das informações digitais; a identificação e controle dos colaboradores, garantindo autenticidade e não repúdio às interações realizadas no âmbito dos sistemas de informação e, por fim, a confiabilidade no armazenamento e na recuperação do conhecimento hospedado em nuvem.

\section{Considerações finais: reflexões sobre o futuro da interdisciplinaridade na gestão do conhecimento}

A natureza interdisciplinar da gestão do conhecimento é de um lado sua força e de outro sua fraqueza. Ela reside na contribuição de uma pluralidade de 


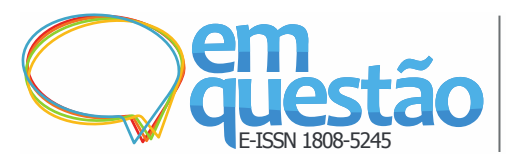

Interfaces disciplinares selecionadas da gestão do conhecimento: características, contribuições e reflexões Lillian Maria Araujo de Rezende Alvares, Jainne Aragão Carvalho Fernandes, Ângelo José Penna Machado, Cleids Maria Lisbôa Cardoso Soares, Tácito Furtado Silva, Mariana Giubertti Guedes Greenhalgh, Eduardo Wallier Vianna

perspectivas, oferecendo uma rica visão da área. Ao mesmo tempo, tantos aportes disciplinares comprometem o entendimento nuclear da área e dispersam sua fundamentação teórica.

Conceitualmente, a gestão do conhecimento está assentada sob os fundamentos teóricos de várias disciplinas científicas e uma forma de compreender e organizar essa contribuição é a perspectiva dos paradigmas humanista, sociotécnico, organizacional e tecnológico de Sagsan (2009). Das disciplinas que podem ser relacionadas a cada paradigma, esta pesquisa aprofundou as contribuições das ciências cognitivas, da estatística, da administração e da economia e da segurança da informação. Das ciências cognitivas, pode-se afirmar que o trato humanista oriundo da filosofia, da pedagogia e da psicologia, entre outras, colabora efetivamente para o ambiente organizacional de maneira geral e para a implantação e melhoria da gestão do conhecimento em particular, sobretudo tendo-se em vista os aspectos da aprendizagem individual e organizacional. Da estatística supõe-se a necessidade de constantes avaliações, interpretações e análises quantitativas da informação cada vez mais complexas. De outro ponto de vista, a área também pode fornecer os elementos para a análise da estrutura da organização, contribuindo para a preparação do ambiente no acolhimento da implantação da gestão estratégica baseada no conhecimento. Para a administração, efetivamente o conhecimento estratégico interno e externo é fator crítico de sucesso. Pelo ângulo dos administradores, o domínio, por um profissional, das práticas de gestão do conhecimento, não restrito apenas a sua área de interesse e atuação, reduz o tempo de decisão, diminui o risco e, consequentemente, aumenta a competitividade. Pelo ângulo da gestão do conhecimento, é para melhorar o ambiente organizacional e para alcançar vantagem competitiva que todos os esforços são envidados. Da economia, observa-se que apesar de a importância dada ao conhecimento ter sido reconhecida de forma tardia como ativo organizacional estratégico, a sociedade, mesmo que implicitamente, sempre esteve vinculada à busca de conhecimento para atingir os seus objetivos e o conhecimento hoje é, de fato, o diferencial que leva a vantagem competitiva. Da segurança da informação, pode-se afirmar que o ambiente cibernético atual 


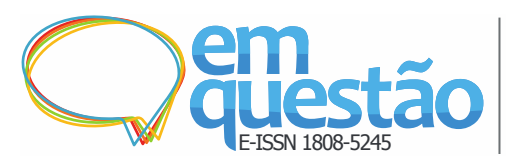

Interfaces disciplinares selecionadas da gestão do conhecimento: características, contribuições e reflexões

Lillian Maria Araujo de Rezende Alvares, Jainne Aragão Carvalho

Fernandes, Ângelo José Penna Machado, Cleids Maria Lisbôa Cardoso Soares, Tácito Furtado Silva, Mariana Giubertti Guedes Greenhalgh, Eduardo Wallier Vianna

exige atenção, tanto aos aspectos técnicos da informação digital, quanto aos aspectos políticos e organizacionais. São muitas as vulnerabilidades e o futuro aponta para ameaças ainda maiores. Para isso, devem-se cumprir no mínimo os requisitos estabelecidos em normas internacionais e por especialistas, como os atributos de segurança de confiabilidade, integridade, disponibilidade, autenticidade, irretratabilidade, conformidade e responsabilidade.

Vários modelos de gestão do conhecimento existem e muitos estão em desenvolvimento. Isso exige que as disciplinas que tratam do tema ainda realizem muito progresso para atender todas as demandas em curso e no porvir. Além do mais, vale lembrar o caráter interdisciplinar da gestão do conhecimento, que se, por um lado, recebe contributos de outras ciências, por outro também deve enriquecê-las e criar relações estruturantes recíprocas.

\section{Referências}

ALONSO, M. A questão do conhecimento na sociedade contemporânea: desafios educacionais. Olhar de professor, Ponta Grossa, v. 2, n. 2, p. 31-41, nov. 1999.

\section{ASSOCIAÇÃO BRASILEIRA DE NORMAS TÉCNICAS. ABNT NBR}

ISO/IEC 27002: tecnologia da informação: técnicas de segurança: código de prática para a gestão da segurança da informação. Rio de Janeiro: ABNT, 2005.

BASKERVILLE, R.; DULIPOVICI, A. The theoretical foundations of knowledge management. Knowledge Management Research \& Practice, London, v. 4, n. 2, p. 83-10, 2006.

DALKIR, K. Knowledge management in theory and practice. Amsterdam: Elsevier, 2005.

DAVENPORT, T. H.; PRUSAK, L. Conhecimento empresarial: como as organizações gerenciam o seu capital intelectual. 4. ed. Rio de Janeiro: Elsevier, 2003.

DRUCKER. P. Sociedade pós-capitalista. 6. ed. São Paulo: Pioneira, 1997.

EQUIPE de Professores da Universidade de São Paulo. Manual de economia. São Paulo: Saraiva, 1991.

FUKUNAGA, F. Gestão do conhecimento: conceitos e definições. São Paulo: Sociedade Brasileira de Gestão do Conhecimento (SBGC), 2017. 
GAGNÉ, R. M. Princípios essenciais da aprendizagem para o ensino. Porto Alegre: Globo, 1980.

GAUTHIER, C.; BISSONNETTE, S. RICHARD, M. Ensino explícito e desempenho dos alunos: a gestão dos aprendizados. Petrópolis: Vozes, 2018. (Coleção Ciências Sociais da Educação)

GLOET, M.; BERRELL, M. The dual paradigm nature of knowledge management: implications for achieving quality outcomes in human resource management. Journal of Knowledge Management, [s.1.], v. 7, n. 1, p. 78-89, 2003.

GONZALEZ, R. V. D. Retenção de conhecimento em serviços. Perspectivas em Ciência da Informação, Belo Horizonte, v. 21, n. 1, p. 42-65, jan./mar. 2016.

GONZALEZ, R. V. D.; MARTINS, M. F. Gestão do conhecimento: uma análise baseada em fatores contextuais da organização. Production, São Paulo, v. 25, n. 4, p. 834-850, out./dez. 2015.

GU, Y. Global Management research: a bibliometric analysis. Scientometrics, Switzerland, v. 61, n. 2, p. 171-190, oct. 2004.

HAZLETT, S-A.; McADAM, R.; GALLAGHER, S. Theory building in knowledge management: in search of paradigms. Journal of Management Inquiry, Thousand Oaks, California, v. 14, n. 1, p. 31-42, 2005.

IGNÁCIO, S. A. Importância da estatística para o processo de conhecimento e tomada de decisão. Nota Técnica Ipardes, Curitiba, n. 6, out. 2010.

INSTITUTO BRASILEIRO DE GEOGRAFIA E ESTATÍSTICA (IBGE). Institucional. Brasília, IBGE, 2019.

IVES, W.; TORREY, B.; GORDON, C. Knowledge management: an emerging discipline with a long history. Journal of Knowledge Management, [s.1.], v. 1, n. 4, p. 269-274, 1998.

KOENIG, M. E. D. Education knowledge management. Information Services and Use, [s.1.], v. 19, p. 17-31, 1999.

KUHN, T. S. A estrutura das revoluções científicas. São Paulo: Perspectivas, 1970.

LOPES, C. E.; MEIRELLES, E. O desenvolvimento da probabilidade e da estatística. In: ENCONTRO REGIONAL DE PROFESSORES DE MATEMÁTICA, 18., 2005, Campinas. Anais [...]. Campinas: Unicamp, 2005. p. 1-8. 
MARSHALL, A. Princípios de economia. São Paulo: Abril Cultural, 1982.

MASTERMAN, M. A natureza de um paradigma. In: LAKATOS, I.; MUSGRAVE, A. A crítica e o desenvolvimento do conhecimento, São Paulo: Cultrix, 1979. p. 72-108.

MEMÓRIA, J. M. P. Breve história da estatística. Brasília: Embrapa, 2004. (Texto para Discussão, n. 21). Disponível em: https://ainfo.cnptia.embrapa.br/digital/bitstream/item/92422/1/sge-texto-21.pdf. Acesso em: 22 jun. 2019.

MORAIS, C. Descrição, análise e interpretação de informação quantitativa: escalas de medida, estatística descritiva e inferência estatística. Bragança: Instituto Politécnico de Bragança, 2010. Disponível em: http://www.ipb.pt/ cmmm/discip/ConceitosEstatistica.pdf . Acesso em: 29 jan. 2019.

NONAKA, I.; TAKEUCHI, H. Criação de conhecimento na empresa: como as empresas japonesas geram a dinâmica da inovação. Rio de Janeiro: Elsevier, 1997.

ORGANIZAÇÃO INTERNACIONAL DE NORMALIZAÇÃO. ISO

30401:2018: Knowledge management systems: requirements. Geneva, Switzerland, 2018.

PINA, P. J. A. Benefícios da gestão do conhecimento nas organizações: estudo de caso. 2010. 108 f. Dissertação (Mestrado em Gestão de Sistema da Informação) - Instituto Universitário de Lisboa, Lisboa, 2010.

PONZI, L. J. The intellectual structure and interdisciplinary breadth of knowledge management: a bibliometric study of its early stage of development. Scientometrics, Switzerland, v. 55, n. 2, p. 259-272, aug. 2002.

PRUSAK, L. Where did knowledge management come from? IBM Systems Journal, Riverton, v. 40, n. 4, p. 1002-1007, feb. 2001.

QUINTAS, P.; LEFRERE, P.; JONES, G. Knowledge management: a strategic agenda. Long Range Planning, [s.1.], v. 30, n. 3, p. 385-391, 1997.

RUIZ GONZÁLEZ, M. A.; FONT GRAUPERA, E.; LAZCANO HERRERA, C. El impacto de los intangibles en la economía del conocimiento. Economía y Desarrollo, La Habana, v. 155, n. 2, p. 119-132, 2015.

SAGSAN. M. Knowledge management discipline: test for an undergraduate program in Turkey. Electronic Journal of Knowledge Management, Sonning Common, v. 7, n. 5, p. 627-636, 2009. 


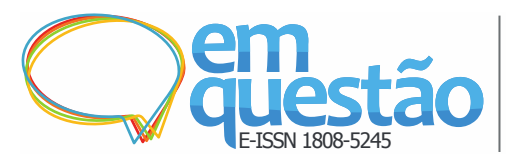

Interfaces disciplinares selecionadas da gestão do conhecimento: características, contribuições e reflexões Lillian Maria Araujo de Rezende Alvares, Jainne Aragão Carvalho Fernandes, Ângelo José Penna Machado, Cleids Maria Lisbôa Cardoso Soares, Tácito Furtado Silva, Mariana Giubertti Guedes Greenhalgh, Eduardo Wallier Vianna

SATTAR, A.; HIGGINS, S. E. Perspectives on education for knowledge management. In: IFLA Council and General Conference, 67., Boston, 2001. Proceedings [...]. Boston: IFLA, 2001.

SCHWARTZ, D. G. Aristotelian view of knowledge management. In: SCHWARTZ, D. G.(ed.) Encyclopedia of knowledge management. 2. ed. New York: IGI Global, 2006a.

SCHWARTZ, D. G. Encyclopedia of knowledge management. London: Idea Group Reference, 2006b.

STANKOSKY, M. A. Advance in knowledge management: university research toward a discipline. In: STANKOSKY, M. A. (org.). Creating the discipline of knowledge management: the latest in university research. London: Routledge, 2005.

STEWART. T. A. Capital intelectual: a nova vantagem competitiva das empresas. Rio de Janeiro: Campus, 1998. 237 p.

TARAPANOFF, K. Técnicas para tomada de decisão nos sistemas de informação. Brasília: Thesaurus, 2000.

VIANNA, E. W.; SOUSA, R. T. B. de. Ciberproteção: a segurança dos sistemas de informação no espaço cibernético. RICI Revista Ibero-Americana de Ciência da Informação, Brasília, v. 10, n. 1, p. 110-131, 2017.

VIGOTSKI, L. S. Psicologia pedagógica. São Paulo: WMF Martins Fontes, 2010.

WALLACE, D. P. Knowledge management: historical and cross-disciplinary themes. Westport: Greenwood Publishing Group, 2007. (Knowledge management series).

\title{
Selected disciplinary interfaces of Knowledge Management: characteristics, contributions and reflections
}

\begin{abstract}
In this study, we analyze the contribution of some of the structuring disciplines of knowledge management from the approach of the four paradigms of knowledge management proposed by Mustafa Sagsan. Such perspective reveals the interdisciplinary breadth of knowledge management, which allows us to understand its theoretical foundations. We chose to analyze the cognitive sciences, as representative of the humanist paradigm; statistics, as representative of the socio-technical paradigm; administration and economics, as representative
\end{abstract}


of the organizational paradigm, and security of digital information as representative of the technological paradigm. We reviewed literature from 2008 to 2018 on the disciplinary interfaces of knowledge management in documents retrieved in the Bielefeld Academic Search Engine (BASE) database, one of the largest scientific information search engines in the world, with more than 140 million indexed documents from more than 6,000 sources, about $60 \%$ of which are available through open access. The results point out that the future of knowledge management will depend even more on the advances obtained in the disciplines under study.

Keywords: Knowledge management. Interdisciplinarity. Paradigms of knowledge management.

Recebido: 15/07/2019

Aceito: 26/10/2019

\footnotetext{
${ }^{1}$ Segundo Piaget (1972), o termo multidisciplinar refere-se a fenômenos de empréstimo ou importação de conhecimento de uma ciência para outra sem levar a modificações na disciplina original. Já o termo interdisciplinar é o intercâmbio mútuo e integração recíproca entre disciplinas de tal modo que exista um enriquecimento de ambas.

${ }^{2}$ Kuhn (1970, p. xi) reconhece que existem casos em que mais de um paradigma podem coexistir em uma ciência. No caso dos paradigmas computacional e orgânico, os autores afirmam que ambos estão em coexistência pacífica. O texto voltará ao assunto mais adiante.

${ }^{3}$ Outro autor que se destaca na matéria é Edgar Morin, na sua obra La méthode, designando paradigma como "[...] quer o princípio, o modelo ou a regra geral, quer o conjunto das representações, crenças, ideias que se ilustram de maneira exemplar ou que ilustram casos exemplares [...]”. MORIN, E. O método IV: as ideias: a sua natureza, vida, habitat e organização. Portugal: Publicações Europa-América, 1992.

${ }^{4}$ Andragogia é a ciência que estuda como os adultos aprendem. O conceito de 1970 de Malcolm Knowles da educação voltada para o adulto hoje já é entendido como uma alternativa à pedagogia clássica e referese à educação centrada no aprendiz para pessoas de todas as idades.

${ }^{5}$ No original: A este proceso se incorpora el conocimiento como un elemento de gran importancia que ocupa un lugar esencial en el crecimiento económico y en la elevación progresiva del bienestar social, pues resulta central en los procesos de innovación y generación de nuevos conocimientos, los que se materializan en nuevos productos, procedimientos y organizaciones, para alimentar el desarrollo de una nación.

${ }^{6} \mathrm{O}$ segmento referente a administração e economia foi baseado na dissertação de mestrado da autora deste artigo Jainne Aragão. Bases conceituais da gestão do conhecimento. 2019. 175 p. Dissertação (Mestrado em Ciência da Informação) - Faculdade de Ciência da Informação, Universidade de Brasília, Brasília, 2019.

${ }^{7}$ World Economic Forum (WEF)

${ }^{8}$ Em inglês, tradicionalmente definido com a sigla CIA (Confidentiality, Integrity, Availability)
} 